\title{
Review Article \\ Recent Advances in the Synthesis and Stabilization of Nickel and Nickel Oxide Nanoparticles: A Green Adeptness
}

\author{
Muhammad Imran Din and Aneela Rani \\ Institute of Chemistry, University of the Punjab, New Campus, Lahore 54590, Pakistan \\ Correspondence should be addressed to Muhammad Imran Din; imrandin2007@gmail.com
}

Received 21 December 2015; Revised 16 May 2016; Accepted 24 May 2016

Academic Editor: Frantisek Foret

Copyright (C) 2016 M. Imran Din and A. Rani. This is an open access article distributed under the Creative Commons Attribution License, which permits unrestricted use, distribution, and reproduction in any medium, provided the original work is properly cited.

Green protocols for the synthesis of nanoparticles have been attracting a lot of attention because they are eco-friendly, rapid, and cost-effective. Nickel and nickel oxide nanoparticles have been synthesized by green routes and characterized for impact of green chemistry on the properties and biological effects of nanoparticles in the last five years. Green synthesis, properties, and applications of nickel and nickel oxide nanoparticles have been reported in the literature. This review summarizes the synthesis of nickel and nickel oxide nanoparticles using different biological systems. This review also provides comparative overview of influence of chemical synthesis and green synthesis on structural properties of nickel and nickel oxide nanoparticles and their biological behavior. It concludes that green methods for synthesis of nickel and nickel oxide nanoparticles are better than chemical synthetic methods.

\section{Introduction}

Nanoparticles (NPs) are cluster of atoms having at least one dimension in the size range of $1-100 \mathrm{~nm}$. Owing to their unique optical, magnetic, catalytic, and electrical properties, they have potential applications in various fields [1]. The physicochemical properties of NPs are different as compared to those of their bulk counterparts owing to the fact that surface area to volume ratio increases and quantum effects become dominant as the size decreases. The increase in surface area to volume ratio alters the mechanical, catalytic, and thermal properties of material [2].

In recent years there is an emerging interest to synthesize magnetic NPs of $\mathrm{Fe}, \mathrm{Co}$, and Ni due to their superior magnetic properties and potential uses in many fields including catalysis, memory storage devices, and sensors. In the field of medicine they are used for magnetically controlled drug delivery, magnetic resonance imaging, and hyperthermia treatment of cancer cells [3-5].

Many physical and chemical methods including coprecipitation [6], sol-gel [7], microemulsion [8], hydrothermal reaction [9], electrospray synthesis [10], and laser ablation [11] are used to synthesize NPs. These methods may produce well defined pure NPs but they have low productivity, high cytotoxicity, low antioxidant potential, and low antimicrobial activity and are not environmental friendly [12].

There is a great concern to search for environmentally benign methods which results in the development of bionanotechnology. Bionanotechnology synthesizes NPs by using biological systems including bacteria, fungi, yeast, plants, and naturally occurring small molecules such as vitamins, proteins, peptides, and reducing sugars [13-16].

The combination of biological principles (i.e., oxidation/reduction) by microbial enzymes or plant phytochemicals with physical and chemical approaches results in the synthesis of NPs with desired functions $[17,18]$. Biological synthesis provides an environmental friendly, simple, inexpensive approach for synthesizing NPs with an added advantage of stabilizing the formed NPs as plant secondary metabolites besides acting as synthetic agents also act as capping agent. Moreover, NPs synthesized by using green chemistry have no or low cytotoxicity as compared to chemically synthesized NPs which makes them efficient carrier of drugs for in vivo drug delivery applications [19].

Herein, we review the work done in the field of green synthesis of $\mathrm{Ni}$ and $\mathrm{NiO} \mathrm{NPs}$ and discuss the role of reaction 
parameters on the structural properties of formed Ni NPs. We also present a comparative overview of influence of chemical synthesis and green synthesis on the $\mathrm{Ni}$ and $\mathrm{NiO}$ NPs structural properties and biological properties.

\section{Properties of Nanoparticles}

The physical and chemical properties of NPs are function of their size and shape and are therefore different as compared to size independent constant physical properties of bulk material. This difference in properties at nanoscale is due to their large surface area which makes them highly reactive and quantum size effects which become dominant at nanoscale. Some of the size dependent properties of NPs are briefly described here:

(i) Band Gap. The band gap between the valence band and conduction band increases as the size of NPs decreases.

(ii) Melting Point. The melting point or phase transition temperature of NPs is low and this decrease becomes more pronounced when the particle size gets below $5 \mathrm{~nm}$.

(iii) Mechanical Properties. The probability of defects is low at nanoscale, due to which their mechanical strength is high and they are characterized as highly tough and hard materials.

(iv) Electrical Properties. The electrical conductivity is influenced in 2 ways at nanoscale. It decreases because of large surface scattering while it may increase because of better ordering.

(v) Optical Properties. Color or optical properties of NPs are highly dependent on the size of particle. This change in color can be explained on the basis of shift of $\lambda_{\mathrm{SPR}}$ to higher wavelengths as the particle size increases in case of plasmonic NPs.

(vi) Magnetic Properties. Due to large surface energy of materials at nanoscale, ferromagnetism vanishes and shifts to supermagnetism.

(vii) Catalytic Properties. The catalytic efficiency of NPs is very high as compared to bulk material due to their large surface area [20].

\section{Significance of Nickel Nanoparticles}

Nickel NPs find potential applications in various fields including electronics, magnetism [21], energy technology [22], and biomedicines [23]. Due to their high reactivity, operational simplicity, and eco-friendly properties they are used to catalyze various organic reactions including chemoselective oxidative coupling of thiols [24], reduction of aldehydes and ketones [25], hydrogenation of olefins [26], synthesis of stilbenes from alcohol through Wittig-type olefination [27], and $\alpha$-alkylation of methyl ketone [28]. They also catalyze certain inorganic reactions like decomposition of ammonia [29]. One of their recent applications is their role in the fabrication of carbon nanotubes (CNTs) [30].
They also find environmental applications in the field of adsorption of hazardous dye and inorganic pollutants and thus play a vital role in the cleanliness of environment [31]. Due to their good antibacterial and anti-inflammatory activities they are used in the field of biomedicine $[19,32]$.

They also show cytotoxicity against cancerous cells as is evident from the distortion of morphology of these cells after their treatment with Ni NPs [23, 33]. The biocompatibility of Ni NPs capped with biomolecules such as glucose is highly increased and these are used as biosensors and heat nonmediator for cancer hyperthermia [34].

\section{Strategies for Nanoparticles Synthesis}

Principally there are 2 approaches used to synthesize NPs including top-down approach and bottom-up approach.

4.1. Top-Down Approach for NPs Synthesis. This method comprises a set of synthetic technologies which synthesize NPs by removing certain parts from a bulk material substrate. The different methods for removal of parts from bulk materials may include chemical, electrochemical, and mechanical methods. The choice of a particular method is based on the material of bulk substrate and desired sizes of NPs. This technique however does not provide a full control on particle size. Top-down method is extended to obtain nanosized domains and coupled the mechanical removing techniques with electrochemical and chemical techniques [35].

4.2. Bottom-Up Approach for NPs Synthesis. This approach consists of set of synthetic technologies which synthesize larger and more complex systems by stacking materials on the top of a base substrate and maintaining good control over molecular structure. One of the basic requirements for this fabrication approach is that there must be strong adhesion forces between the surface layer and base substrate and for this purpose surfactants are added which increase the adhesion between surface layer and base substrate [35].

\section{Mechanism for Biosynthesis of Metal and Metal Oxide Nanoparticles}

The secondary metabolites of plants and microbial/fungal enzymes are responsible for the reduction of metal ions into metal atoms. The metal salts like nitrates, chlorides, oxides, and sulphates have high reduction potential due to attachment of metal with the chloride, oxide, and sulphide parts and their tendency to donate electrons. As a result of both these factors electronic density on the conjugative salts of metal increases. So metals in their ionic form can easily get detached from their anionic part and get reduced into stable form by using plant/microbial/fungal extract. The secondary metabolites of plant including alkaloids, flavonoids, polyphenols, and terpenoids act as chelator to metal ions and reduce them into zero-valent states. Mostly the $-\mathrm{OH}$ group of polyphenols and flavonoids develop coordination with metal ions, while in case of microbial mediated synthesis 


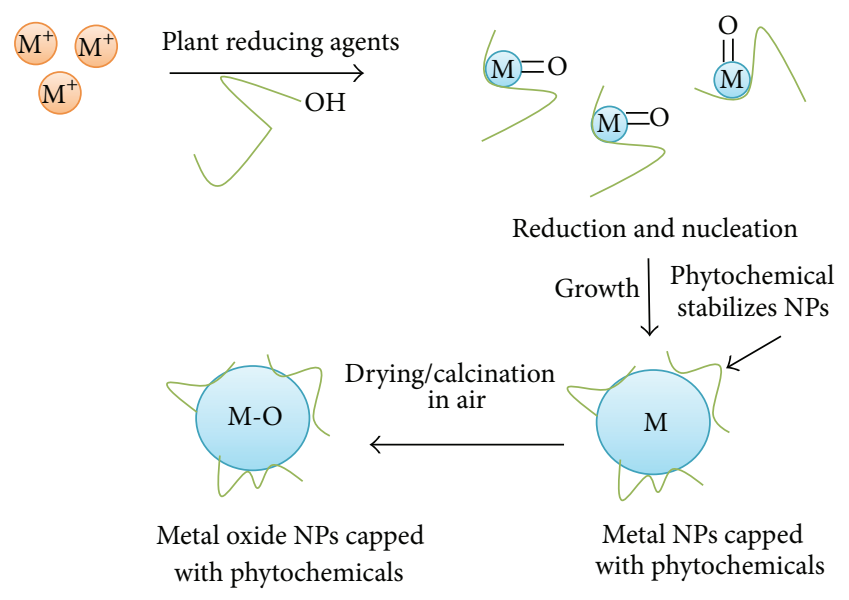

FIGURE 1: Mechanism of plant mediated synthesis of metal and metal oxide nanoparticles.

the reductase enzyme of bacterial or fungal cell wall donates electron for reduction of metal ions.

We can describe mechanism of plant mediated synthesis of metal and metal oxide NPs by considering the following three phases: (1) activation phase involves the reduction of metal ions and reduced metal atoms undergo nucleation; (2) growth phase involves the spontaneous coalescence of small adjacent NPs into larger size NPs, that is, Ostwald ripening (a process in which NPs are directly formed through heterogeneous nucleation and growth and further reduction of metal ion); this process enhances the thermodynamic stability of NPs; (3) termination phase decides the final shape of NPs. In case of metal oxide NPs the end product is airdried or calcined in air to get final metal oxide NPs [36]. The schematic diagram for mechanism of NPs synthesis by plants is shown in Figure 1.

The mechanism of microbial mediated synthesis of metal and metal oxide NPs is also described by the following three phases: (1) the metal cation is trapped by bacterial or fungal cell wall due to electrostatic interactions between negatively charged cell wall and positively charged metal cation; (2) the cell wall then releases reductase enzyme which reduced the metal cations into metal atom; (3) these atoms then aggregate and form metal NPs. The formed NPs might be capped by the biomolecules of bacterium or fungi which prevent further aggregation of metal NPs and finally the formed NPs diffused out from cell wall [37].

In case of metal oxide NPs the end product is air-dried or calcined in air to get final metal oxide NPs. The schematic diagram for mechanism of NPs synthesis by plants is shown in Figure 2.

As the growth phase duration increases, aggregation of NPs occurs and nanohexahedrons, nanotubes, nanoprisms, and different kinds of irregularly shaped NPs are formed. The aggregation occurred because of stronger binding energy between 2 metal atoms as compared to atom-solvent binding energy. The aggregation of NPs is prevented somewhat by the secondary metabolites of plants and fungal/microbial biomolecules/enzymes which act as capping agent and stabilize the formed NPs [36]. Mallikarjuna and coworkers reported that the hydroxyl and carbonyl groups of amino acid residues or proteins can strongly adhere to metal NPs as capping agent and prevent them from aggregation [38].

The crystal shape of metal and metal oxide NPs is a function of rate of growth in different crystallographic directions. The surface energy of crystal faces varies because the capping agents interact differently with different faces. This results in anisotropic growth of metal crystals, while in case of isotropic growth, rate of reaction is high and spherical shaped crystals are obtained. In case of higher rate of reaction, process of nucleation dominates over growth and vice versa. The size of NPs also increases when their growth is anisotropic. However, the dimensions of anisotropically growing nanomaterials (e.g., nanoprisms) can be controlled by adjusting the experimental conditions like $\mathrm{pH}$, ratio of metal ion and reducing agent, irradiation time and its strength (in case of microwave heating), and reaction time. Figure 3 shows the different shapes of NPs crystal that result from their isotropic and anisotropic growth [39].

\section{Biosynthesis of Nickel Nanoparticles}

Very few literature is available on the biological synthesis of $\mathrm{Ni}$ and NiO NPs as compared to chemical synthesis. The physical and chemical methods of NPs fabrication are accompanied by some disadvantages like high cost, complexity (involving multiple steps), use of harmful organic chemicals, and environmental pollution. So there is a great need to develop alternative eco-friendly and low cost fabrication methods for NPs. Nature has devised numerous processes for the fabrication of micro- and nanoscaled inorganic materials using naturally occurring biomolecules or microorganisms and plant extract as reducing agent. Green synthesis of NPs is a type of bottom-up technique where main reaction taking place is reduction/oxidation. There are 3 basic requirements for biosynthesis of NPs including (i) choice of proper solvent, (ii) choice of an eco-friendly reducing agent, and (iii) choice of nontoxic stabilizing agent for NPs. Thus by choosing proper solvent, surfactant and reductant biosynthesis produces NPs with controlled morphology without producing any toxic environmental pollutant [35].

In plant mediated synthesis of Ni NPs commonly extract of different parts of plants is used as a reducing agent, while in some other cases rather than using the extract either whole plant is grown on a metal substrate or an entire part of plant is soaked in metal solution. Here, in situ reduction of metal ions occurs and their morphology can also be controlled as porous parts of plants also act as biotemplate [40]. Some naturally occurring biomolecules such as glucose, sucrose, or plant secretions may also work as good reducing agent and stabilizing agents and thus are used to fabricate Ni NPs $[16,34,41]$.

6.1. Biosynthesis of Ni Nanoparticles Using Plants. In recent years the fabrication of NPs using plants has fascinated the researchers because of its simple, cost effective, fast, and 


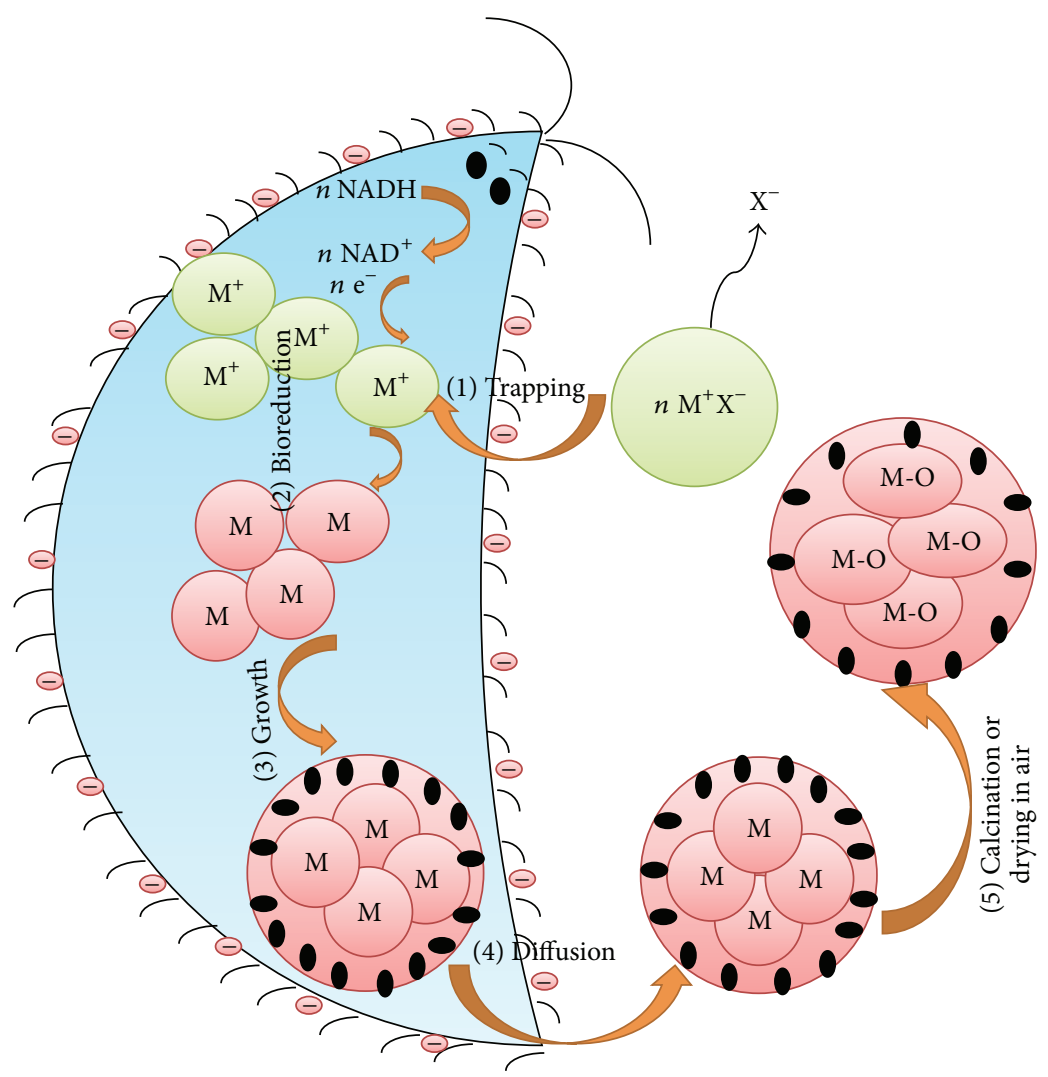

FIGURE 2: Mechanism of microbes mediated synthesis of metal and metal oxide nanoparticles.
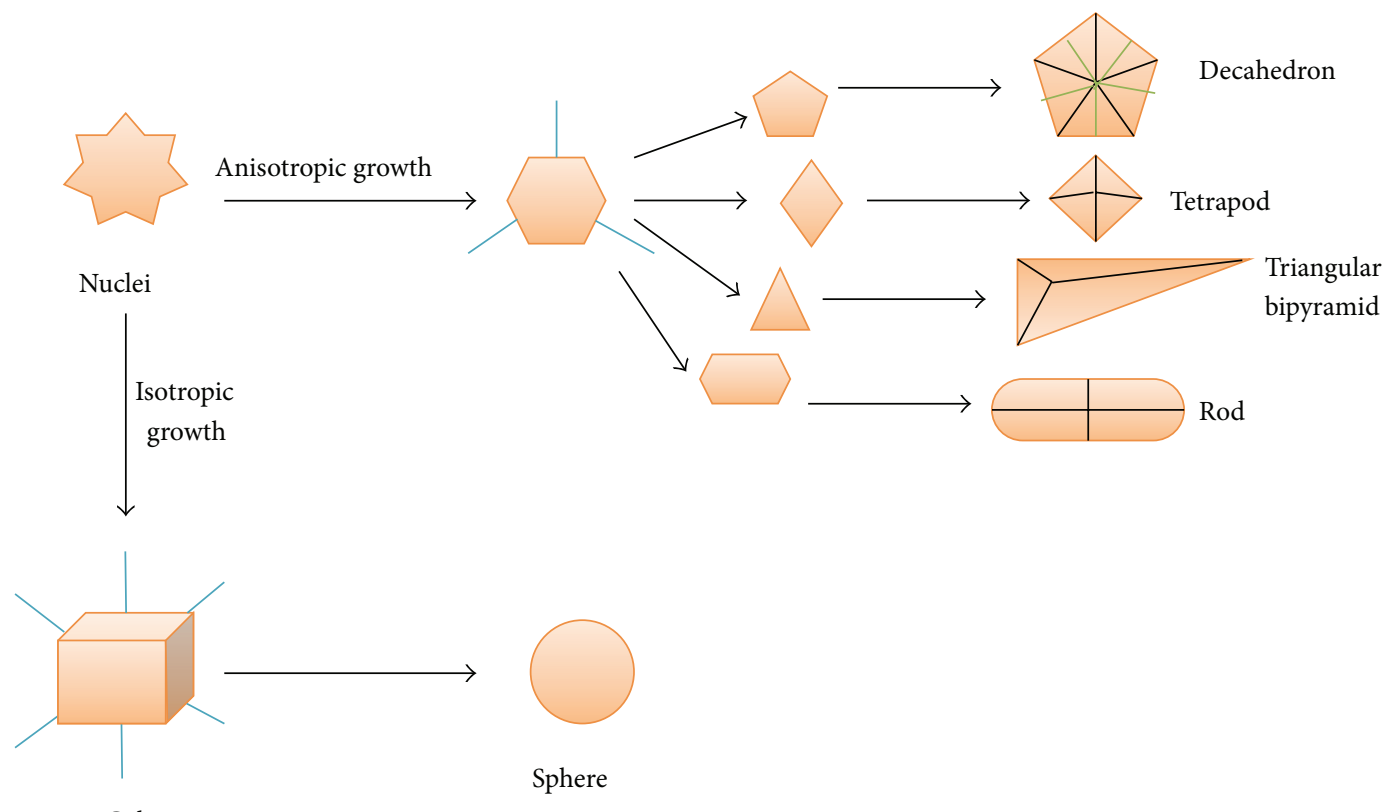

Sphere

Cube

FIGURE 3: Growth of nanoparticles by different ways and their resulting geometrical shapes. 
TABLE 1: Optimal reaction parameter conditions for maximum percentage removal of dyes and inorganic pollutants.

\begin{tabular}{lccc}
\hline Adsorbate & $\mathrm{pH}$ & $\begin{array}{c}\text { Contact } \\
\text { time }(\mathrm{min})\end{array}$ & $\begin{array}{c}\text { Initial conc. of dyes and } \\
\text { pollutants }(\mathrm{mg} / \mathrm{L})\end{array}$ \\
\hline $\mathrm{CV}$ & 8 & 40 & 40 \\
$\mathrm{EY}$ & 3 & 20 & 20 \\
$\mathrm{OR}$ & 3 & 30 & 30 \\
$\mathrm{NO}_{3}{ }^{-}$ & 7 & 10 & 10 \\
$\mathrm{SO}_{4}{ }^{-}$ & 7 & 10 & 10 \\
\hline
\end{tabular}

environmental friendly protocol [42]. Biosynthesis is a single step technique for synthesis of NPs which provides stable NPs of different morphologies. The rate of production is rapid compared to microorganisms based biosynthesis of NPs. Infra-red spectroscopy showed that secondary metabolites including terpenoids, flavones, pyrones, aldehydes, amides, and carboxylic acids derived from plant extracts are responsible for reduction of metal salts into their respective NPs [43]. Only few research articles are reported so far on the synthesis of Ni NPs using plants. Different parts of plants such as leaves and roots are used for synthesizing Ni NPs.

6.1.1. Fabrication of Ni NPs Using Leaf Extract of Plants. Chen et al. [44] reported the synthesis of face-centered cubic $\mathrm{Ni}$ $\mathrm{NPs}$ by reducing aqueous solution of $\mathrm{Ni}\left(\mathrm{NO}_{3}\right)_{2}$ with aqueous extract of Medicago sativa (alfalfa). The typical synthetic method of Ni NPs involved the vigorous stirring of precursor solution with alfalfa solution at $60^{\circ} \mathrm{C}$ for 4 hours. The reaction was carried out at $60^{\circ} \mathrm{C}$ because at room temperature it is difficult to completely reduce $\mathrm{Ni}(\mathrm{II})$ into $\mathrm{Ni}(0)$. Then NPs solution was freeze-dried for $24 \mathrm{~h}$ in order to obtain Ni NPs powder.

Pandian and coworkers [31] synthesized Ni nanoparticles by using aqueous solution of $\mathrm{Ni}\left(\mathrm{NO}_{3}\right)_{2} \cdot 6 \mathrm{H}_{2} \mathrm{O}$ as precursor and leaf extract of Ocimum sanctum as reducing agent as well as stabilizing agent. The $\mathrm{Ni}(\mathrm{II})$ ions were reduced into $\mathrm{Ni}(0)$ by hydrated electrons of $O$. sanctum aqueous leaf extract and $\mathrm{Ni}(0)$ nuclei were formed. These $\mathrm{Ni}(0)$ atoms then aggregate and Ni NPs were formed. A UV/Vis spectrum of the sample was recorded and peak centered at $395 \mathrm{~nm}$ corresponding to $\mathrm{Ni}$ NPs confirmed the formation of Ni NPs. The XRD pattern was recorded for Ni NPs confirming that Ni NPs have face centered cubic structure and average particle size was $30 \mathrm{~nm}$ as calculated by Debye-Scherrer equation. This particle size showed good agreement with that calculated by SEM (particle size was 15 and $36 \mathrm{~nm}$ ) and by TEM (particle size was 12 and $36 \mathrm{~nm})$.

These Ni NPs were then used to adsorb organic dyes including crystal violet (CV), 2-naphthol orange or Orange II $(\mathrm{OR})$, eosin $\mathrm{Y}(\mathrm{EY})$, and anionic contaminants sulfate $\left(\mathrm{SO}_{4}{ }^{2-}\right)$ and nitrate $\left(\mathrm{NO}_{3}{ }^{-}\right)$from aqueous solution. Their adsorption capacity was studied as a function of change in $\mathrm{pH}$, Ni NPs dosage, contact time, and initial concentration of pollutants and dyes. The optimal conditions of $\mathrm{pH}$, contact time, initial concentration of dyes, and inorganic pollutants for maximum adsorption capacity of Ni NPs are summarized in Table 1.
It was observed that adsorption of dye and inorganic pollutants increased by using large initial concentration of both Ni NPs and pollutants and increasing contact time of adsorbent and adsorbate.

6.1.2. Fabrication of Nickel Nanoparticles Using Plants as Biotemplate. The leaves and petals of plants are porous and they serve as biotemplate for fabrication of Ni NPs. This method of Ni NPs synthesis is advantageous since it has good control on size of particle and Ni NPs formed are not prone to agglomeration. Kar and Ray [40] developed a green method for fabrication of metallic Ni NPs using petals of Hibiscus rosa-sinensis as biotemplate and reducing agent. The petals of hibiscus flowers are porous and beneath these pores tunnels are present which supply nutrients and moisture to whole parts of petal. These pores adsorbed $\mathrm{NiCl}_{2} \cdot 6 \mathrm{H}_{2} \mathrm{O}$ which then subsequently reduced into Ni NPs by $\mathrm{C}_{2} \mathrm{H}_{4}$ which is one of the products obtained during pyrolysis of petals. The formation of Ni NPs was confirmed by the attraction of end product of reaction towards the magnet. The size of obtained Ni NPs was in the range of $10 \mathrm{~nm}-200 \mathrm{~nm}$ and was coated with the mesoporous carbon which prevents them from agglomeration. The formed Ni NPs were stable even after 20 days.

\subsection{Fabrication of Bioconjugated Nickel Nanoparticles Using} Naturally Occurring Biomolecules. The magnetic nanoparticles of nickel are prone to oxidation and therefore most of synthesis protocols utilize toxic and expensive organic media and hydrophobic capping agents to prevent agglomeration and surface oxidation of magnetic nanoparticles [45]. The stability of nickel nanoparticles in aqueous media is a challenge.

The naturally occurring biomolecules such as vitamins, reducing sugars, and plant secretions containing polyphenols are good antioxidants and they can potentially be applied to produce stable dispersions of nanoparticles in aqueous media where they act both as reductant and as capping agents. Moreover, the biocompatibility of formed NPs is also increased which thus increases their applications in the field of drug delivery.

Raj and Viswanathan [16] reported the synthesis of $\mathrm{Ni}$ NPs in ethanolic media by using sucrose as reducing agent and vegetable oil as capping agent. In order to establish suitable precursor and reducing agent several precursors (nickel nitrate, nickel acetate, and nickel chloride) and reducing agents (hydrazine, sodium borohydride, and sucrose) were investigated. The calculated heat of reaction showed that nickel nitrate was best precursor and sucrose was best reducing agent.

Bioconjugated NPs have wide range of applications in the biomedical field as NPs become more biocompatible for in vivo applications and often used as luminescence tagging, labeling, imaging, and drug delivery [46-48]. Some work has been done in the direction to synthesize bioconjugated $\mathrm{Ni}$ NPs in aqueous media using environmentally benign reducing and capping agent.

Vaseem et al. [34] synthesized highly water-stable bioconjugated glucose-capped nickel nanoparticles (G-Ni NPs) 
through aqueous solution process by using glucose both as a reducing agent and as a capping agent in the presence of liq. $\mathrm{NH}_{3}$. Due to their enhanced biocompatibility these were used as biosensors and heat nonmediator for cancer hyperthermia. The mechanism involved in the synthesis of GNi NPs was proposed as follows: firstly by the addition of liq. $\mathrm{NH}_{3}$ into $\mathrm{Ni}\left(\mathrm{NO}_{3}\right) \cdot 6 \mathrm{H}_{2} \mathrm{O}$ and glucose solution, green color ppt. of $\mathrm{Ni}(\mathrm{OH})_{2}$ were formed. By the further addition of liq. $\mathrm{NH}_{3}$ these ppt. dissolved and transparent green color solution is formed which was due to formation of $\left[\mathrm{Ni}\left(\mathrm{NH}_{3}\right)_{4}\right]^{2+}$ complex. This complex was refluxed in ambient atmosphere at $80^{\circ} \mathrm{C}$ for $2 \mathrm{~h}$. In the presence of liq. $\mathrm{NH}_{3}$ the aldehyde group of glucose oxidized into carboxylate ion and resulting free electrons reduced $\left[\mathrm{Ni}\left(\mathrm{NH}_{3}\right)_{4}\right]^{2+}$ complex into $\mathrm{Ni}$ metal. Usually, glucose remains in open chain format; however in aqueous solution it transforms its structure into cyclic chair form. So, in addition to being acting as a reducing agent, here, it also acts as capping agent by developing complexation with $\mathrm{Ni}$ NPs through its five -OH groups. It is considered that at high $\mathrm{pH}$ condition surface of Ni NPs oxidizes to develop a negative charge $\left(\mathrm{Ni}-\mathrm{O}^{-}\right)$. Usually, in aqueous media metal NPs have negative surface charges; that is why it is considered that hydrogen bonding interactions develop between Ni NPs surface and glucose which facilitates capping of Ni NPs.

6.3. Characterization of Ni Nanoparticles. UV-Visible spectroscopy (UV-Vis) [31], Fourier transformation infrared spectroscopy (FTIR) [44], X-ray diffraction (XRD) [23, 40], scanning electron microscopy (SEM) [31], transmission electron microscopy (TEM) [44], zeta potential measurement [19], thermogravimetric analysis (TGA) [41], X-ray photoelectron spectrometry (XPS) [44], photoluminescence (PL) [41], energy-dispersive X-ray spectroscopy (EDS) [34], and atomic force microscope (AFM) [41] are literature reported fundamental characterization techniques for Ni NPs [31].

Ni NPs are plasmonic; that is, they show surface plasmon resonance (SPR) and absorption band in the range of $300 \mathrm{~nm}-400 \mathrm{~nm}$ is due to SPR of Ni. The phenomenon of SPR occurred because the metallic NPs physically absorbed light and as a result of this absorption conduction electrons of metal undergo coherent oscillation. This happened when the frequency of incident photon becomes equal to natural frequency of surface electrons; at this frequency amplitude of oscillation becomes maximum and this frequency is called SPR. The absorbance of light is measured with the help of $\mathrm{UV} / \mathrm{Vis}$ spectrophotometer.

The shape of SPR band, its width, and its spectral position depend on the size of NPs and their size distribution. The SPR peak shows a red shift in position as the size of NPs increases, and blue shift is observed when particle size decreases. When the NPs are monodisperse in size distribution then shape of SPR peak is symmetrical and it became broad and split into two bands when size distribution became nonuniform [49].

Mamuru et al. synthesized Ni NPs using aqueous leaf extract of Annona squamosa as reducing agent and aqueous $\mathrm{NiO}$ solution as precursor salt at neutral $\mathrm{pH}$. They monitored the formation of Ni NPs by visual color change of reaction mixture and by $\mathrm{UV} / \mathrm{Vis}$ spectroscopy. The color of reaction mixture changes from light blue to dark brown indicating the formation of Ni NPs. Their formation was further confirmed by taking their UV/Vis spectrum in which absorbance maximum at $285 \mathrm{~nm}$ was assigned to SPR peak for Ni NPs. The plasmonic band had symmetrical shape which suggested that formed NPs were uniform and well-dispersed [50].

FTIR spectroscopy is used to investigate the biomolecules responsible for reduction of metal salt into metal NPs and their subsequent growth inactivation through the capping effect of these biomolecules. For this purpose, the FTIR spectrum of plant extract and metal NPs is recorded. The absorption band corresponding to biomolecules which are responsible for bioreduction should appear only in extract spectrum and should disappear in NPs spectrum. This helps not only in the identification of biomolecules responsible for bioreduction but in proposing the mechanism of reaction.

Mamuru and Jaji synthesized Ni NPs using $\mathrm{NiCl}_{2} \cdot 6 \mathrm{H}_{2} \mathrm{O}$ as a salt precursor and leaf extract of Moringa oleifera as a reducing agent. The change in color of solution from light blue to dark reddish brown indicated the formation of Ni NPs which was further confirmed by observing their SPR peak at $297 \mathrm{~nm}$. They tried to explore the biomolecules responsible for bioreduction of $\mathrm{Ni}(\mathrm{II})$ ions into $\mathrm{Ni}(0)$ by recording the FTIR spectrum of both leaf extracts of $M$. oleifera and $\mathrm{Ni}$ NPs. It was observed that IR band at $1636 \mathrm{~cm}^{-1}$ was the only one band that was present in $M$. oleifera spectrum and was absent in IR spectrum of Ni NPs. All other bands of M. oleifera were present in Ni NPs spectrum. This band was of amino aryl ketones, that is, anthraquinones, so it is possible that this is the biomolecule which was responsible for reduction. The presence of anthraquinone was confirmed by the appearance of cherish red color after the addition of $25 \% \mathrm{NH}_{3}$ solution into leaf extract which is a confirmatory test for anthraquinones [49].

Another way to identify the biomolecules responsible for bioreduction is to record the FTIR spectrum of plant/microbial extract before and after bioreduction. The bands of those biomolecules which are responsible for bioreduction change their position in the spectrum recorded after bioreduction. In this regard, Chen and coworkers tried to explore the biomolecules of alfalfa grass which were responsible for the bioreduction of $\mathrm{Ni}(\mathrm{II})$ ions and stabilization of $\mathrm{Ni}(0) \mathrm{NPs}$ by recording IR spectrum of extract before and after bioreduction. The bioreduction of $\mathrm{Ni}$ (II) was caused by flavonoids and reducing sugars of extract as indicated by the change in band position of $\mathrm{C}-\mathrm{O}$ group of flavonoids and reducing sugar. The band was observed at longer wavelength after bioreduction as compared to the band recorded before bioreduction. The IR result suggesting flavonoids and reducing sugar as reductant was further supported by low amount of these biomolecules in extract measured after bioreduction as compared to their amount measured before bioreduction [44].

$\mathrm{XRD}$ is used for the identification, purity, and quantitative analysis of NPs. The phase of NPs is determined by recording 
the peaks at $2 \theta$ value; these peaks give the value of crystal planes for particular type of NPs. By comparing the position and intensity of these diffraction peaks with Joint Committee on Powder Diffraction Standard (JCPDS) card number (each type of metal has specific JCPDS card number) one can identify the NPs and their phase (spherical, wurtzite, etc.). The intensity of XRD spectrum peaks is function of particle crystallinity. When the NPs have good crystallinity then intense and sharp peaks are observed and vice versa. The NPs size can also be calculated using Scherrer equation; when particle size is large then XRD patterns become broad [51]:

$$
D=\frac{0.98 \lambda}{\beta \cos \theta},
$$

where $D$ is particle size, $\lambda$ is wavelength $(\mathrm{Cu} \mathrm{K} \alpha), \beta$ is FWHM, and $\theta$ is diffraction angle.

Pandian et al. recorded the XRD spectrum for Ni NPs synthesized by reducing $\mathrm{Ni}$ (II) ions with leaf extract of Ocimum sanctum. They observed 5 distinct diffraction peaks in XRD spectrum at $2 \theta$ values $37.32^{\circ}, 44.82^{\circ}, 47.92^{\circ}, 63.11^{\circ}$, and $72.97^{\circ}$ and the peak at $2 \theta$ value $44.82^{\circ}$ showed maximum intensity. Their resulting miller indices (111) and (200) affirmed that the NPs were face centered cubic (fcc) Ni. The average particle size calculated by Debye-Scherrer formula was found to be $30 \mathrm{~nm}$ [31].

SEM is used to study the surface morphology and composition of NPs by scanning the surface with high energy electron beam, produced by heated filament. Angajala et al. [52] synthesized Ni NPs by using the aqueous leaf extract of Aegle marmelos Correa (AmC) as a reducing agent and aqueous solution of $\mathrm{NiCl}_{2} \cdot 6 \mathrm{H}_{2} \mathrm{O}$ as a precursor salt. The formation of Ni NPs was indicated by color change of solution from dark green to light green. The surface morphology of formed Ni NPs was investigated by employing SEM. The results indicated that NPs were polycrystalline in nature with average particle size of $80-100 \mathrm{~nm}$ having triangular shape. Their SEM images exhibited that NPs were capped by organic biomolecule layer which is derived from leaf extract of AmC having surface functional $-\mathrm{OH}$ groups that take part in bioreduction of $\mathrm{Ni}(\mathrm{II})$ ions into $\mathrm{Ni}(0) \mathrm{NPs}$, besides acting as stabilizing and capping agent. Within the agglomerates the NPs were not in direct contact and aggregation was seen only between the outer surfaces of organic material surrounding the Ni NPs.

TEM is used for the identification of details of internal composition of NPs including their shape, size, size distribution, and defects. Mariam et al. synthesized Ni NPs by using leaf extract of Azadirachta indica and NiO NPs using Psidium guajava leaf extract. Their morphology was determined by taking their TEM images. It was exhibited by their TEM images that both $\mathrm{Ni}$ and NiO NPs were spherical in shape and their size was $<100 \mathrm{~nm}$. Their size distribution was also narrow and NPs showed aggregation in order to reduce the total surface energy of system [23].

6.4. Effect of Reaction Parameters on Structural Properties of $\mathrm{Ni} N \mathrm{~N}$. The structural properties of Ni NPs such as their size and shape are function of reaction parameters including concentration of leaf extract, concentration of precursor salt, temperature, $\mathrm{pH}$ of medium, and reaction time. Chen et al. studied the effect of concentration of alfalfa extract on the size of Ni NPs. It was observed that not only particle size increased but also widening of size distribution occurred at high concentration of extract. This was due to the fact that by increasing the concentration of extract concentration of reducing agents increased for the same concentration of precursor salt and thus size of $\mathrm{Ni}(0)$ particles grew with more and more $\mathrm{Ni}(0)$ produced by bioreduction [44].

6.5. Impact of Green Synthesis on the Biological Behavior of $\mathrm{Ni}$ NPs. NPs synthesized by green routes are more biocompatible and nontoxic because in this route the reducing agent and stabilizing agents for NPs are plants or microbial reducing sugars and flavonoids which do not have cytotoxic effects. In this regard Sudhasree et al. [19] carried out comparative study between conventional chemical method using hydrazine as a reducing agent and biological method using Desmodium gangeticum (DG) root extract for Ni NPs synthesis. DG possesses antioxidant and antiapoptotic properties. They compared the antioxidant potential and cytotoxicity and antimicrobial activity of Ni NPs synthesized by both routes.

The antioxidant potential of Ni NPs was assayed by studying the scavenging assay of 2,2-diphenyl-1-picrylhydrazyl $(\mathrm{DPHH})$ and superoxide radical. DPHH violet color in the presence of radical changes to yellow color on hydrogenation. The higher percentage scavenging was observed in case of $\mathrm{Ni}$ NPs synthesized by green route (NiGs) as compared to $\mathrm{Ni}$ NPs synthesized by chemical methods (NiCs). This was attributed to the presence of an additional moiety in NiGs which was phenolic compounds and the presence of phenolic compounds was confirmed by high superoxide scavenging activity of NGs (phenolic compounds possess $\mathrm{O}_{2}{ }^{-}$scavenging activity) [19].

NPs have ability to cross physiological barriers and thus can enter and damage cells of living organisms. The cytotoxicity of both types of NPs was checked by both in vitro and in vivo methods. In both these methods the activity of lactate dehydrogenase (LDH) which was released from plasma membrane because of discharge from damaged cell as a result of NPs presence was monitored to check the cytotoxicity of Ni NPs. The in vitro assay was carried out on epithelial cell line and in vivo assay was carried out on LLC PK1 kidney cell lines of male rate. The results showed that NiGs are nontoxic as compared to NiCs as confirmed by the low activity of LDH (formation of formazon by LDH catalyzed reduction of tetrazolium salt) in case of NiGs nanoparticles [19].

The antibacterial activity of NPs is a function of chemical composition, shape, concentration, photoactivation, and size of NPs. The antibacterial activity of NiGs and NiCs NPs, precursor salt, and reducing agent was assayed on Gram negative and Gram positive bacteria using agar gel diffusion method. Two control experiments, one positive control and one negative control, were also conducted to check antimicrobial activity. The large value for zone of inhibition in case of NiGs (Figure 4) confirmed that NiGs have high antibacterial 


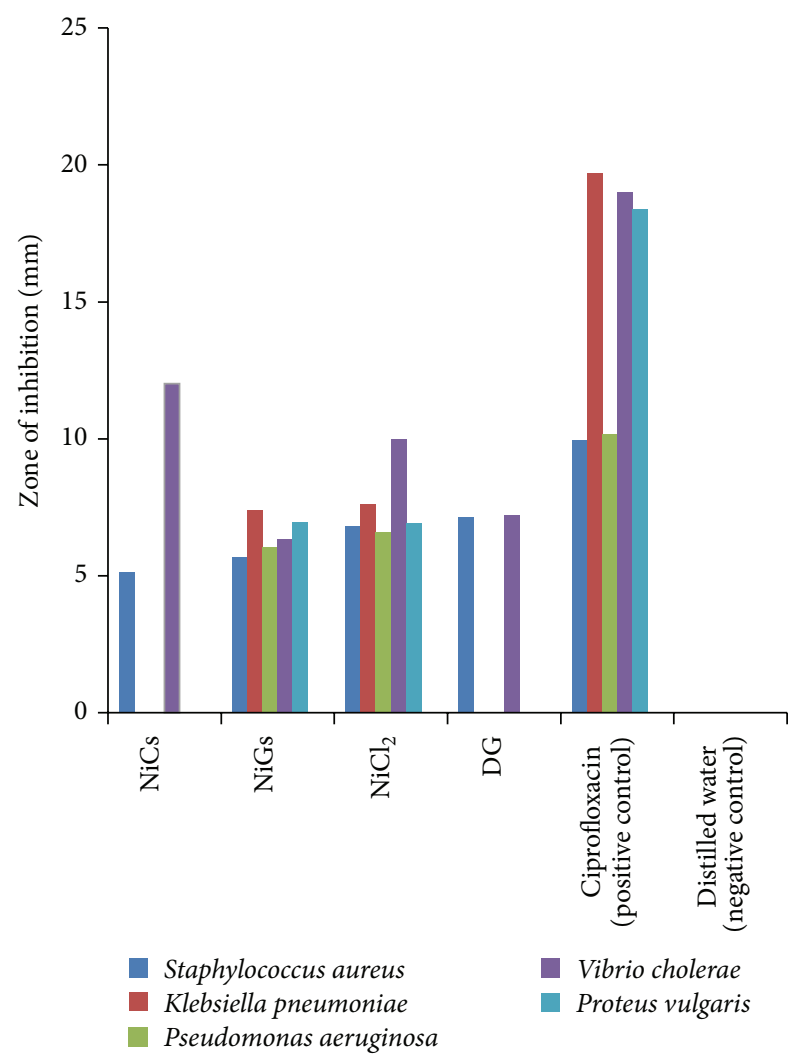

FIgUre 4: Comparison of antibacterial activities of NiGs, NiCs, $\mathrm{NiCl}_{2}$, DG, positive control, and negative control.

activity as compared to that of NiCs, precursor salt, and DG extract [19]. Thus NiGs were nontoxic and possess higher stability and higher antioxidant and antimicrobial potential than chemically synthesized Ni NPs [19].

Helen and Rani [53] synthesized Ni NPs using aqueous solution of nickel sulphate and root tuber extract of Dioscorea (Elephant Yam) as reducing and capping agent. The color change of solution from blue to yellow indicated the formation of Ni NPs. The UV/Vis peak of Ni NPs was centered at $207 \mathrm{~nm}$. The antibacterial activity of these Ni NPs was assayed by disc diffusion method against 4 bacterial strains including Staphylococcus aureus and Bacillus cereus (Gram positive) and Klebsiella pneumonia and Escherichia coli (Gram negative). The Ni NPs were most effective against Staphylococcus aureus and were least effective against Klebsiella pneumonia as indicated by their zone of inhibition. The result of effectiveness of Ni NPs against different microbes is shown in Figure 5.

Angajala and Radhakrishnan [32] synthesized Ni NPs by using aqueous leaf extract of Aegle marmelos Correa (AMC) and also checked their synergistic efficacy with $\beta$ sitosterol to induce anti-inflammation and compared their anti-inflammatory activity with the different leaf extracts of AMC by employing 2 tests, albumin denaturation assay and membrane stabilization test. $\beta$-Sitosterol is a plant sterol identified from the AMC aqueous leaf extract and it possesses anti-inflammatory properties. The -OH group of $\beta$-sitosterol develops bonding with AMC leaf extracts' synthesized $\mathrm{Ni}$

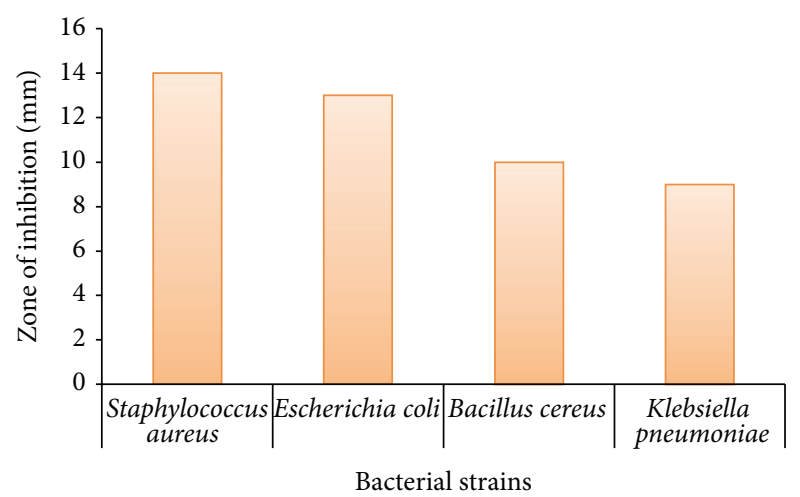

FIgURE 5: Comparison of effectiveness of Ni nanoparticles against different bacterial strains.

NPs surface. The intracellular inhibitory effect of Ni NPs associated $\beta$-sitosterol upon entering into inflammatory sites results because they develop association with receptor site by generating therapeutic effects and together assist the growth of peripheral blood lymphocytes. It was observed that the therapeutic efficacy of Ni NPs associated $\beta$-sitosterol was higher as compared to $\beta$-sitosterol of aqueous leaf extract. This was due to high surface area of Ni NPs as compared to aqueous leaf extract of AMC, which cause the $\beta$-sitosterol to remain on the surface of Ni NPs rather than in the interior of particle and therefore enhance its exposure to receptor sites in order to produce therapeutic effect.

Mariam et al. [23] synthesized Ni NPs using leaf extract of Azadirachta indica and NiO NPs using Psidium guajava leaf extract. The synthesized nanoparticles showed cytotoxicity against HT29 cell line (human colon adenocarcinoma). Two types of experiment were conducted on human colon adenocarcinoma cells; one of them was control experiment (untreated cells) and the other was test experiment in which cells were treated with $\mathrm{Ni}$ and $\mathrm{NiO}$ NPs. The cytotoxicity of Ni NPs and in turn the percentage viability of cancer cells were assayed by conducting a colorimetric assay, MMT assay (3-[4,5-dimethylthiazol-2-yl]-2,5-diphenyl tetrazolium bromide). MMT is a yellow tetrazol which can be reduced to insoluble crystals of purple formazan by the action of oxidoreductase enzymes of living cells. The insoluble crystals of formazan can be solubilized by adding dimethyl sulfoxide and absorbance of purple solution is quantified by recording spectra at certain wavelength $(540 \mathrm{~nm})$ using a spectrophotometer. The absorbance is directly proportional to number of living cells. The results of Mariam et al. [23] study showed that absorbance was decreased in cell culture treated with Ni NPs (concentration $>6.25 \mu \mathrm{g} / \mathrm{mL}$ ) as compared to that of untreated cells. These results were further supported by the morphological analysis of treated and controlled cells. The control cells showed smooth and regular surface with normal morphology, whereas $\mathrm{Ni}$ and $\mathrm{NiO}$ treated cells showed changes in cell morphology due to cell swelling and breaking as a result of apoptosis.

Nanoparticles are efficient drug carriers for both in vitro and in vivo applications. Chen and coworkers [33] checked the synergistic impact of Ni NPs with antitumor drug 
Verbascoside (VB) both in vitro and in vivo on the induction of apoptosis of K562 cancer cells. They conducted four types of experiments; one of them was control experiment in which cells were not treated and the other 3 experiments involved the treatment of cells with VB-Ni NPs, Ni NPs alone, and VB alone for $72 \mathrm{~h}, 48 \mathrm{~h}$, and $24 \mathrm{~h}$, respectively. The rate of apoptosis for in vitro drug and NPs treated cells was checked by identifying the characteristics feature of apoptotic nuclei like fragmented DNA and condensed chromosomes using fluorescence microscope. The result showed that rate of apoptosis was higher in VB-Ni NPs treated cells as compared to that of alone $\mathrm{Ni}$ and VB treated cells. The in vivo studies on the cancerous cells of female mice were conducted on the same line as was done for in vitro study, but here a magnet was also placed under mice skin near cancer cells. In this study, again rate of apoptosis was higher in VB-Ni NPs treated cells. These results suggested that $\mathrm{Ni}$ was transferred from VB-Ni into cancer cells through the action of magnetic field generated by the magnet placed near the cancer cells where it suppresses the growth of tumor cells and kills the tumor cells together with drug.

\section{Nickel Oxide (NiO) Nanoparticles}

Metal elements are capable of forming large diversity of compounds with oxygen (metal oxides). These metal oxides can be insulators, semiconductors, or conductors depending on their structural geometries which give rise to particular electronic structure. Metal oxides are widely used in the manufacturing of fuel cells, microelectronic circuits, piezoelectric devices, sensors, and corrosion resistant coatings and as catalysts. The metal oxide NPs possess distinct physical and chemical characteristics because of their smaller size and highly dense edge or corner surface sites. In any material, particle size affects the 3 most crucial groups of fundamental properties; first group is of structural properties, namely, cell parameters and lattice symmetry; second group is of electronic properties and the above mentioned two properties then induce changes in physical and chemical properties of materials. Among the metal oxide NPs, magnetic metal oxide NPs are gaining much interest because their properties can be modified according to their shape and size [54].

Recently, NiO NPs are studied widely because of their electrocatalysis, high chemical stability, superconductance characteristics, and electron transfer capability [55]. $\mathrm{NiO}$ is a p-type semiconductor metal oxide having a band gap ranging from 3.6 to $4.0 \mathrm{eV}$ depending upon the nature of defects and their density. It is an antiferromagnetic material having Neel temperature $T_{\mathrm{N}}$ of $\sim 523 \mathrm{~K}$ and besides a high isoelectric point of $\sim 10.7$, it also shows high ionization. The potential applications of $\mathrm{NiO}$ are in various areas like in water treatment, gas sensing, electrochemical performance, and antimicrobial activities. Numerous methods to fabricate $\mathrm{NiO}$ NPs have been reported in the literature which includes solvothermal [56], precipitation-calcination [57], chemical precipitation [58], microwave-assisted hydrothermal [59], and thermal decomposition $[56,60]$ methods. These methods involve ample reactants and starting materials, draggy procedures,

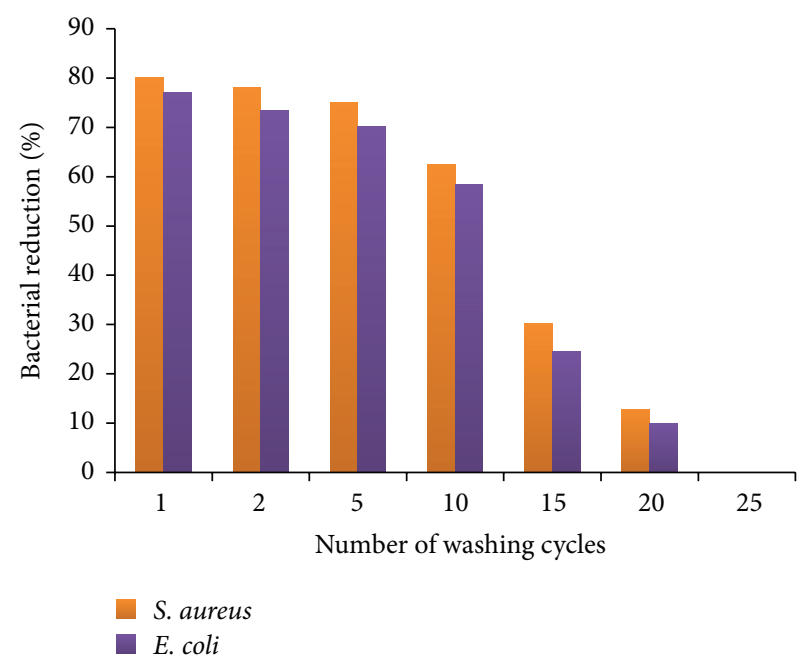

FIGURE 6: Effect of washing cycles on the antibacterial activity of $\mathrm{NiO}$ nanoparticles coated cotton fabric.

and complex apparatus. Therefore, recently environmental benign green chemistry approach is used to synthesize $\mathrm{NiO}$ NPs.

7.1. Fabrication of $\mathrm{NiO}$ Nanoparticles by Using Plant Extract. Yuvakkumar and coworkers [61] synthesized $\mathrm{NiO}$ nanocrystals by utilizing nickel nitrate as precursor and rambutan peel waste as reducing and stabilizing agent and then checked their antibacterial activity by coating them on cotton fabric surface.

The probable mechanism for synthesis of $\mathrm{NiO}$ nanocrystals from rambutan peel extract is the formation of nickelellagate complex through ligation of phenolic hydroxyl group and ester oxygen atom of polyphenols with nickel at $\mathrm{pH}$ 5-7. The complex after calcination at $450^{\circ} \mathrm{C}$ decomposes and $\mathrm{NiO}$ nanocrystals are formed. The active components of rambutan are vitamins, polyphenols, flavonoids, and alkaloids which serve as antioxidants, antiviral, and radical scavengers. Among these active components the polyphenols such as ellagic acid, geranin, and corilagin are present in large amounts and serve as antioxidants.

These $\mathrm{NiO}$ nanocrystals were then adsorbed on cotton fabric by pad-dry-cure and citric acid acts as crosslinker in this adsorption. The fabric untreated and treated with $\mathrm{NiO}$ nanocrystals was tested for antibacterial activity against Staphylococcus aureus (Gram positive bacteria) and Escherichia coli (Gram negative bacteria) by employing a disc diffusion method. The mechanism of antibacterial activity is described as follows: by the action of UV and visible light activation of $\mathrm{NiO}$ occurs which leads to formation of electron-hole pairs. By the hydrolysis and redox reactions hydrogen peroxide is produced which can enter cell membrane and kill bacteria. The antibacterial activity of fabric treated with NiO NPs was significant after 10 washes but after that the percentage of bacterial reduction was very low and after 20 washes this activity completely diminishes as shown in Figure 6. 
Thema and coworkers synthesized single phase Bunsenite NiO NPs using Agathosma betulina leaves extract. The formed NPs were characterized for their surface/interface and volume room temperature characteristics by various analytical techniques. The photodiode behavior in the NIR spectral range for standard blade made film of pressed p-type $\mathrm{NiO}$ NPs onto n-type Si substrate was studied. The average size of $\mathrm{NiO}$ NPs was $26.7 \pm 0.4 \mathrm{~nm}$ as calculated by their TEM and the crystalline aspects of these NPs were confirmed by observing many diffraction rings with strong diffraction spots using selective area electron diffraction (SAED). The elemental composition of formed NPs was confirmed by recording EDS spectrum which revealed the presence of $\mathrm{Ni}$ and $\mathrm{O}$ in the nanopowder. The presence of $\mathrm{C}$ and $\mathrm{Cu}$ elements was assigned copper grid and its carbon coating. The crystallographic analysis of formed NPs was carried out by recording their XRD profile. The obtained crystal planes were corresponding to cubic $\mathrm{NiO}$ phase which is also called Bunsenite phase. The average diameter of NiO NPs using Debye-Scherrer formula was within the range of 15.23$23.15 \mathrm{~nm}$ which was with close approximation with that size calculated by TEM.

$\mathrm{NiO}$ is a p-type semiconductor material having a weak absorption band in the visible region and an electrical resistivity on the basis of $\mathrm{Ni}$ cation vacancies concentration. There are no such $\mathrm{Ni}$ vacancies in the stoichiometric $\mathrm{NiO}$; however at nanoscale there is probably a nonstoichiometric state of Ni depletion. The presence of these defects at nanoscale is attributed to the breakage of 3D symmetry at the NPs surface. Thus, any $\mathrm{n}$-Si/p-type NiO NPs film heterojunction could show a photodiode behavior in the UV/Vis/NIR spectral range. The photodiode behavior of p-type NiO NPs deposited on n-type $\mathrm{Si}$ in the NIR spectral range was studied by applying Choi et al. photodiode experiment with these NPs. The normal incidence irradiation of photodiode was carried out employing a $\mathrm{Hg}$ lamp having a monochromator which covered the spectral range of $290-1100 \mathrm{~nm}$. The $\mathrm{p}-\mathrm{NiO} / \mathrm{n}-$ Si reverse biased diode generated photocurrent at numerous wavelengths which covers the UV/Vis/NIR spectral range. By observing photo $I-V$ profiles (photocurrent-voltage profiles) it is revealed that red illumination (748 and $650 \mathrm{~nm}$ ) generated highest photoresponse followed by blue $(430 \mathrm{~nm})$ and zero current in dark. This can be explained in terms of the fact that the penetration depth of blue light in Si is smaller than red light so a smaller number of photocarriers are generated by blue light compared to that of red light which resulted in lower photocurrent in case of blue light illumination [55].

7.2. Fabrication of NiO Nanoparticles by Using Microbes. Microbes such as bacteria, yeast, and fungi are potential candidates that act as reductant and stabilizing agents for fabrication of nanoparticles. Although the rate of production of microbial synthesized nanoparticles is slower as compared to that of nanoparticles synthesized by using plant extracts they offer certain advantages like economic viability, simple scaling up, easy processing, and biomass handling.
7.2.1. Preparation of Microbial Extract. The general method reported in the literature for the preparation of microbial extract involved the culturing of microbes on an appropriate broth medium followed by their incubation at suitable temperature and rpm on a rotary shaker for set number of days specific for microbes. Then culture is centrifuged at suitable rpm for specific time and supernatant is utilized for fabrication of Ni NPs. Incubation of fungi is carried out at $150 \mathrm{rpm}$ and temperature of $25^{\circ} \mathrm{C}$ for 5 days [62], while bacteria are incubated at $200 \mathrm{rpm}$ and temperature of $30^{\circ} \mathrm{C}$ for 120 hours [63]. The dead fungal biomass can be prepared by autoclaving the live biomass and then drying it at $50^{\circ} \mathrm{C}$ till it becomes crispy. The uniform size biomass particles are obtained after grinding the biomass [62].

7.2.2. Fabrication of NiO NPs Using Fungi. Both living and dead fungal biomass can be used for fabrication of NPs. Use of dead fungal biomass is advantageous as it can be stored for longer period of time and does not require nutrients and growth media and also it has limited toxicity. One of the advantages of fungus mediated green synthesis of NPs is that large surface area can be recovered by optimum growth of mycelia. Moreover, the fungal biomass can tolerate metal toxicity by adsorbing the metal species on their cell wall which is composed of chitosan, chitin, amino group phosphates, glucan, lipids, sulphates, phospholipids and hydroxides, and so forth. These functional groups serve as binding sites for biosorption of metals [62].

One of the major dilemmas of this century is the increased contamination of natural aquatic bodies and sediments with toxic metals. During the last decade the introduction of $\mathrm{Ni}$ in the environment has been enhanced due to increased smelting and mining activities. The interaction between microbes and metals has been well established and the capability of microbes to accumulate and/extract metals is already used in bioremediation by the biosorption of toxic metals. However the mechanism behind this phenomenon has not been well established. Fungi are attractive candidates for biosorption of metals as they are capable of growing under extreme conditions of temperature, $\mathrm{pH}$, and nutrient availability and at high concentration of metal [64].

Salvadori and coworkers [62] synthesized NiO NPs by using nickel chloride as precursor and dead, dried, and living biomass of filamentous fungus Aspergillus aculeatus $\left(\mathrm{MIC}=2000 \mathrm{mg} \mathrm{L}^{-1}\right)$ as reducing agent. Among the three types of fungal biomass used in this experiment maximum adsorption capacity and hence maximum resistance to metal toxicity were exhibited by dead biomass. The required doses of biomass and precursor solution were shaken under suitable reaction conditions and then the $\mathrm{Ni}(\mathrm{II})$ solution was separated from biomass by vacuum filtration using Millipore membrane. The obtained NiO NPs were analyzed through various techniques. The energy-dispersive $\mathrm{X}$-ray spectroscopic analysis revealed the presence of proteins which may serve as capping agent on the NiO NPs surface in the form of film.

The same group of researchers synthesized NiO NPs by the biosorption of $\mathrm{Ni}(\mathrm{II})$ ions on the Hypocrea lixii fungus 
$\left(\mathrm{MIC}=1473 \mathrm{mg} \mathrm{L}^{-1}\right)$ living, dried, and dead biomass. The $\mathrm{Ni}$ (II) retention capacity of $\mathrm{Ni}$ for dead biomass was highest for dead biomass which indicated that dried and live biomass were susceptible to toxicity generated by high concentration of metal. The TEM and HRTEM micrographs of fraction of dead biomass loaded with NiO NPs revealed that NPs were present on the fungal cell wall both extracellularly and intracellularly through biosorption. The micrographs revealed that because of autoclaving process ultrastructural changes like shrinkage of cytoplasm were present both in $\mathrm{NiO}$ loaded dead biomass and in control sample. The average diameter of extra- and intracellular NiO fabricated NPs was 3.8 and $1.25 \mathrm{~nm}$ while their shape was spherical in both cases.

The mechanism for both above mentioned synthetic methods of NiO NPs by fungi is not fully elucidated. However, a 2-step mechanism was proposed; in first step adsorption of $\mathrm{Ni}$ (II) occurred with fungal cell wall through its amide group and then their reduction into metallic $\mathrm{Ni}$ by the enzymes of fungal cell wall. In the second step $\mathrm{Ni}$ was oxidized into $\mathrm{NiO}$ by the $\mathrm{H}_{2} \mathrm{O}$ and $\mathrm{O}_{2}$ present in the medium. The proteins/peptides of fungal cell wall acted as capping agent for formed NPs. This was confirmed by the EDX pattern of $\mathrm{NiO} \mathrm{NPs}$ in which additional peaks for $\mathrm{C}, \mathrm{N}$, and $\mathrm{O}$ were present and further by their FTIR analysis in which band for N-H of amide II linkages of proteins/polypeptides at $1535 \mathrm{~cm}^{-1}$ was shifted to $1542 \mathrm{~cm}^{-1}$; this indicated the deformation of $\mathrm{N}-\mathrm{H}$ group as it capped the $\mathrm{NiO}$ NPs [64].

Ullah and coworkers [65] synthesized NiO NPs by using nickel nitrate hex hydrate as precursor and Rhizopus nigricans fungus as reducing and stabilizing agent. The fungus was obtained from bread and its fine pieces were added into precursor solution. The $\mathrm{pH}$ of solution was adjusted by using $1 \mathrm{M} \mathrm{NaOH}$ solution. The solution after stirring for 5 hours was kept overnight and then filtered by using Whatman filter paper. This filtrate was then calcined at $500^{\circ} \mathrm{C}$ for 5 hours and the obtained sample was ground tiny particles. The characterization of NiO NPs revealed that the NPs are polydisperse with an average diameter of $\sim 40 \mathrm{~nm}$. Since these NPs are polydisperse, monodisperse NPs can be obtained by varying the experimental conditions like $\mathrm{pH}$, temperature, and concentration of reductant and precursor.

7.2.3. Fabrication of NiO NPs Using Bacteria. Nickel is widely used in steel, batteries, and electroplating industries and the $\mathrm{Ni}$ (II) ions discharged from these industries are carcinogenic so there is a need to reduce or remove their concentration in industrial effluents. The conventional effluent treatment methods are not efficient since they mostly introduce secondary pollutants in environment besides being costly. So there is a great concern to develop cost-effective and environmentally benign treatment methods which can either completely remove soluble $\mathrm{Ni}$ (II) ions from industrial discharge or convert them into insoluble separable form such as $\mathrm{NiO}$ which is insoluble in water.

Sathyavathi and coworkers [63] converted the soluble $\mathrm{NiSO}_{4}$ present in discharged effluents of electroplating industry into insoluble $\mathrm{NiO}$ by using cells of nickel resistant
Microbacterium sp. MRS-1 which was isolated from effluent of nickel electroplating industry (effluent diluted with sodium chloride was plated on nutrient agar and incubated for bacterium growth at $30^{\circ} \mathrm{C}$ ). The bioremediation of $\mathrm{Ni}(\mathrm{II})$ ions was achieved by incubating the bacterium with industrial effluent having $\mathrm{Ni}(\mathrm{II})$ of $2172 \mathrm{mg} / \mathrm{L}$ concentration at $30^{\circ} \mathrm{C}$ for $120 \mathrm{~h}$ at $200 \mathrm{rpm}$, followed by centrifugation of bacterial culture in order to remove cells of bacteria. The pale green precipitates were obtained at the bottom of flask which were then collected, washed, dried, and then characterized. The formation of metal oxide NPs is explained by efflux mechanism, which involves the extracellular fabrication of nanomaterials and by considering the role of metabolism dependent and biologically controlled processes which play major role in the nucleation and deposition of inorganic particles. The characterized precipitates were of NiO NPs having size in the range of $100 \mathrm{~nm}-50 \mathrm{~nm}$ with a flower like structure. Thus, this method provides a green route for the remediation of soluble toxic $\mathrm{Ni}$ (II) ions with an efficiency of $95 \%$ nickel removal.

7.3. Characterization of NiO Nanoparticles. UV-Visible spectroscopy (UV-Vis) [23], atomic force microscope (AFM), Xray diffraction (XRD) [65], X-ray photoelectron spectrometry (XPS) [62], transmission electron microscopy (TEM) [61], scanning electron microscopy (SEM) [65], and energydispersive X-ray spectroscopy (EDS) [62] are fundamental techniques reported in literature for the characterization of $\mathrm{NiO}$ nanoparticles.

The NiO NPs synthesized extracellularly from Microbacterium sp. MRS-1 showed broad UV/Vis absorption band around $370-450 \mathrm{~nm}$. The NiO NPs and functional groups of bacterial cell wall were studied by FTIR spectroscopy. The intense IR band at $580 \mathrm{~cm}^{-1}$ was assigned to $\mathrm{Ni}$ $\mathrm{O}$ vibrations and present in both NIPE (NiO fabricated by the reaction of electroplating industrial effluent with MRS-1) and $\mathrm{NiO}$ (fabricated by the reaction of $\mathrm{NiSO}_{4}$ with MRS-1) and was absent in control (MRS-1 present in a solution without $\mathrm{Ni}(\mathrm{II})$ ions). The strong absorption peaks at $1024.34 \mathrm{~cm}^{-1}$ and $1064.74 \mathrm{~cm}^{-1}$ were assigned to amine group and these peaks suggested the role of amine group of bacterial cell wall in the adsorption of metal ions through hydrogen bonding and electrostatic interactions [63].

Salvadori et al. [62] fabricated film of NiO NPs coated on the surface of dead biomass of fungus and recorded the SEM images of dead biomass before and after coating of NiO NPs. It was observed that after binding of NiO NPs the surface of biomass becomes modified. The EDS spectra of biomass were also recorded before and after $\mathrm{NiO}$ formation and the spectra recorded after formation of NiO NPs gave a signal not only for $\mathrm{Ni}$ but also for $\mathrm{C}, \mathrm{N}$, and $\mathrm{O}$ which suggested the presence of proteins on the surface of NiO NPs. The proteins act as capping agents which stabilize the NiO NPs and are also responsible for the organization of $\mathrm{NiO} \mathrm{NPs}$ on the surface of dead biomass of fungus in the form of film. 


\section{Conclusion}

This paper provides an overview of green synthesis of nickel and nickel oxide nanoparticles by using plant extract, microbial extract, and naturally occurring biomolecules. Although all these green protocols for $\mathrm{Ni}$ and $\mathrm{NiO}$ nanoparticles synthesis have their own advantages and limitations use of plants extract as reductant is more beneficial as compared to microbial extract because of rapid rate of production of nanoparticles with former green reductant. However, all these green protocols for synthesis of $\mathrm{Ni}$ and $\mathrm{NiO}$ NPs were simple, efficient, and eco-friendly and did not require ample reactants, draggy procedures, and complex apparatus which were required in case of conventional chemical synthetic methods. The synthesis of nickel and nickel oxide nanoparticles by green chemistry is beneficial due to eco-friendliness, economic prospects, feasibility, enhanced biocompatibility, low cytotoxicity, and high antioxidant and high antimicrobial activity of formed nanoparticles. These features help in commercialization of $\mathrm{Ni}$ and $\mathrm{NiO} \mathrm{NPs}$ in the fields of environmental cleaning and nanomedicine.

\section{Future Perspectives}

$\mathrm{Ni}$ and $\mathrm{NiO}$ nanoparticles with different structural properties and effective biological effects can be fabricated using new green protocols in coming days. The control over particle size and in turn size dependent properties of $\mathrm{Ni}$ and $\mathrm{NiO}$ NPs will open the new doors of their applications. There is a great potential of porous plant petals to act as soft biotemplate for Ni NPs which prevents them from agglomeration together holding good control over particle size. Only one plant has been reported as biotemplate for Ni NPs till date [40] so there is a great need to carry out more research in this direction. The work done so far on the green synthesis of $\mathrm{Ni}$ and NiO NPs is much less as compared to green protocols used in the synthesis of noble metal nanoparticles. Literature is available for selection of plants extracts as reducing agent for the synthesis of Ni NPs and NiO NPs [19, 23, 31, 32, $44,49,50,52,53,55,61]$. The microbial mediated synthesis of Ni NPs is not reported yet but the future of this field is bright as reports are present on $\mathrm{NiO}$ NPs production using microbial reduction [63] and researcher can synthesize Ni NPs with some modifications in the protocols used for $\mathrm{NiO}$ NPs production through this route. Despite much work on plant and microbial mediated synthesis of NPs in this decade, the exact mechanism for their synthesis is not fully known and this is the major barrier in commercialization of these protocols. So, in order to scale up these protocols to industrial level the focus of a green chemist should not be only to synthesize NPs but also to fully explore the chemistry involved in synthesis.

\section{Competing Interests}

The authors declare that they have no competing interests.

\section{References}

[1] M. A. Albrecht, C. W. Evans, and C. L. Raston, "Green chemistry and the health implications of nanoparticles," Green Chemistry, vol. 8, no. 5, pp. 417-432, 2006.

[2] J. M. DeSimone, "Practical approaches to green solvents," Science, vol. 297, no. 5582, pp. 799-803, 2002.

[3] H. Rui, R. Xing, Z. Xu, Y. Hou, S. Goo, and S. Sun, "Synthesis, functionalization, and biomedical applications of multifunctional magnetic nanoparticles," Advanced Materials, vol. 22, no. 25, pp. 2729-2742, 2010.

[4] I. Brigger, C. Dubernet, and P. Couvreur, "Nanoparticles in cancer therapy and diagnosis," Advanced Drug Delivery Reviews, vol. 54, no. 5, pp. 631-651, 2002.

[5] A. K. Gupta and M. Gupta, "Cytotoxicity suppression and cellular uptake enhancement of surface modified magnetic nanoparticles," Biomaterials, vol. 26, no. 13, pp. 1565-1573, 2005.

[6] K. Petcharoen and A. Sirivat, "Synthesis and characterization of magnetite nanoparticles via the chemical co-precipitation method," Materials Science and Engineering B: Solid-State Materials for Advanced Technology, vol. 177, no. 5, pp. 421-427, 2012.

[7] F. Jia, L. Zhang, X. Shang, and Y. Yang, "Non-aqueous solgel approach towards the controllable synthesis of nickel nanospheres, nanowires, and nanoflowers," Advanced Materials, vol. 20, no. 5, pp. 1050-1054, 2008.

[8] D.-H. Chen and S.-H. Wu, "Synthesis of nickel nanoparticles in water-in-oil microemulsions," Chemistry of Materials, vol. 12, no. 5, pp. 1354-1360, 2000.

[9] D. Chen and R. Xu, "Hydrothermal synthesis and characterization of nanocrystalline $\gamma-\mathrm{Fe}_{2} \mathrm{O}_{3}$ particles," Journal of Solid State Chemistry, vol. 137, no. 2, pp. 185-190, 1998.

[10] S. Basak, D.-R. Chen, and P. Biswas, "Electrospray of ionic precursor solutions to synthesize iron oxide nanoparticles: modified scaling law," Chemical Engineering Science, vol. 62, no. 4, pp. 1263-1268, 2007.

[11] G. W. Yang, "Laser ablation in liquids: applications in the synthesis of nanocrystals," Progress in Materials Science, vol. 52, no. 4, pp. 648-698, 2007.

[12] B. Nagaraj, N. B. Krishnamurthy, P. Liny, T. K. Divya, and R. Dinesh, "Biosynthesis of gold nanoparticles of Ixora coccinea flower extract \& their antimicrobial activities," International Journal of Pharma and Bio Sciences, vol. 2, no. 4, pp. 557-565, 2011.

[13] M. Kowshik, S. Ashtaputre, S. Kharrazi et al., "Extracellular synthesis of silver nanoparticles by a silver-tolerant yeast strain MKY3," Nanotechnology, vol. 14, no. 1, pp. 95-100, 2003.

[14] M. N. Nadagouda and R. S. Varma, "Green and controlled synthesis of gold and platinum nanomaterials using vitamin B2: density-assisted self-assembly of nanospheres, wires and rods," Green Chemistry, vol. 8, no. 6, pp. 516-518, 2006.

[15] A. V. Singh, B. M. Bandgar, M. Kasture, B. L. V. Prasad, and M. Sastry, "Synthesis of gold, silver and their alloy nanoparticles using bovine serum albumin as foaming and stabilizing agent," Journal of Materials Chemistry, vol. 15, no. 48, pp. 5115-5121, 2005.

[16] K. J. A. Raj and B. Viswanathan, "Synthesis of nickel nanoparticles with fcc and hcp crystal structures," Indian Journal of Chemistry, vol. 50, no. 2, pp. 176-179, 2011.

[17] R. C. Monica and R. Cremonini, "Nanoparticles and higher plants," Caryologia, vol. 62, no. 2, pp. 161-165, 2009. 
[18] A. Ahmad, P. Mukherjee, S. Senapati et al., "Extracellular biosynthesis of silver nanoparticles using the fungus Fusarium oxysporum," Colloids and Surfaces B: Biointerfaces, vol. 28, no. 4, pp. 313-318, 2003.

[19] S. Sudhasree, A. Shakila Banu, P. Brindha, and G. A. Kurian, "Synthesis of nickel nanoparticles by chemical and green route and their comparison in respect to biological effect and toxicity," Toxicological and Environmental Chemistry, vol. 96, no. 5, pp. 743-754, 2014.

[20] N. Krishnamurthy, P. Vallinayagam, and D. Madhavan, Engineering Chemistry, PHI Learning Pvt. Ltd, 2014.

[21] T. Hyeon, "Chemical synthesis of magnetic nanoparticles," Chemical Communications, vol. 9, no. 8, pp. 927-934, 2003.

[22] R. Karmhag, T. Tesfamichael, E. Wäckelgård, G. A. Niklasson, and M. Nygren, "Oxidation kinetics of nickel particles: comparison between free particles and particles in an oxide matrix," Solar Energy, vol. 68, no. 4, pp. 329-333, 2000.

[23] A. A. Mariam, M. Kashif, S. Arokiyaraj et al., "Bio-synthesis of $\mathrm{NiO}$ and Ni nanoparticles and their characterization," Digest Journal of Nanomaterials and Biostructures, vol. 9, no. 3, pp. 1007-1019, 2014.

[24] A. Saxena, A. Kumar, and S. Mozumdar, "Ni-nanoparticles: an efficient green catalyst for chemo-selective oxidative coupling of thiols," Journal of Molecular Catalysis A: Chemical, vol. 269, no. 1-2, pp. 35-40, 2007.

[25] F. Alonso, P. Riente, and M. Yus, "Hydrogen-transfer reduction of carbonyl compounds promoted by nickel nanoparticles," Tetrahedron, vol. 64, no. 8, pp. 1847-1852, 2008.

[26] A. Dhakshinamoorthy and K. Pitchumani, "Clay entrapped nickel nanoparticles as efficient and recyclable catalysts for hydrogenation of olefins," Tetrahedron Letters, vol. 49, no. 11, pp. 1818-1823, 2008.

[27] F. Alonso, P. Riente, and M. Yus, "Wittig-type olefination of alcohols promoted by nickel nanoparticles: synthesis of polymethoxylated and polyhydroxylated stilbenes," European Journal of Organic Chemistry, vol. 2009, no. 34, pp. 6034-6042, 2009.

[28] F. Alonso, P. Riente, and M. Yus, "Alcohols for the $\alpha$-alkylation of methyl ketones and indirect aza-wittig reaction promoted by nickel nanoparticles," European Journal of Organic Chemistry, vol. 2008, no. 29, pp. 4908-4914, 2008.

[29] X.-K. Li, W.-J. Ji, J. Zhao, S.-J. Wang, and C.-T. Au, "Ammonia decomposition over $\mathrm{Ru}$ and $\mathrm{Ni}$ catalysts supported on fumed $\mathrm{SiO}_{2}, \mathrm{MCM}-41$, and SBA-15," Journal of Catalysis, vol. 236, no. 2, pp. 181-189, 2005.

[30] Y. Li, B. Zhang, X. Xie, J. Liu, Y. Xu, and W. Shen, "Novel Ni catalysts for methane decomposition to hydrogen and carbon nanofibers," Journal of Catalysis, vol. 238, no. 2, pp. 412-424, 2006.

[31] C. J. Pandian, R. Palanivel, and S. Dhananasekaran, "Green synthesis of nickel nanoparticles using Ocimum sanctum and their application in dye and pollutant adsorption," Chinese Journal of Chemical Engineering, vol. 23, no. 8, pp. 1307-1315, 2015.

[32] G. Angajala and S. Radhakrishnan, "A review on nickel nanoparticles as effective therapeutic agents for inflammation," Inflammation and Cell Signaling, vol. 1, no. 3, 2014.

[33] M. Chen, Y. Zhang, B. Huang et al., "Evaluation of the antitumor activity by $\mathrm{Ni}$ nanoparticles with verbascoside," Journal of Nanomaterials, vol. 2013, Article ID 623497, 6 pages, 2013.
[34] M. Vaseem, N. Tripathy, G. Khang, and Y.-B. Hahn, "Green chemistry of glucose-capped ferromagnetic hcp-nickel nanoparticles and their reduced toxicity," RSC Advances, vol. 3, no. 25, pp. 9698-9704, 2013.

[35] M. Singh, S. Manikandan, and A. Kumaraguru, "Nanoparticles: a new technology with wide applications," Research Journal of Nanoscience and Nanotechnology, vol. 1, no. 1, pp. 1-11, 2011.

[36] V. V. Makarov, A. J. Love, O. V. Sinitsyna et al., "'Green' nanotechnologies: synthesis of metal nanoparticles using plants," Acta Naturae, vol. 6, no. 20, pp. 35-44, 2014.

[37] M. Rai and N. Duran, Metal Nanoparticles in Microbiology, Springer Science \& Business Media, Berlin, Germany, 2011.

[38] K. Mallikarjuna, G. Narasimha, G. R. Dillip et al., "Green synthesis of silver nanoparticles using Ocimum leaf extract and their characterization," Digest Journal of Nanomaterials and Biostructures, vol. 6, no. 1, pp. 181-186, 2011.

[39] S. Singh, A. Bharti, and V. K. Meena, "Green synthesis of multi-shaped silver nanoparticles: optical, morphological and antibacterial properties," Journal of Materials Science: Materials in Electronics, vol. 26, no. 6, pp. 3638-3648, 2015.

[40] A. Kar and A. K. Ray, "Synthesis of nano-spherical nickel by templating hibiscus flower petals," Journal of Nanoscience and Nanotechnology, vol. 2, no. 2, pp. 17-20, 2014.

[41] A. Dutta and S. K. Dolui, "Tannic acid assisted one step synthesis route for stable colloidal dispersion of nickel nanostructures," Applied Surface Science, vol. 257, no. 15, pp. 68896896, 2011.

[42] P. Raveendran, J. Fu, and S. L. Wallen, "A simple and 'green' method for the synthesis of $\mathrm{Au}, \mathrm{Ag}$, and $\mathrm{Au}-\mathrm{Ag}$ alloy nanoparticles," Green Chemistry, vol. 8, no. 1, pp. 34-38, 2006.

[43] A. K. Mittal, Y. Chisti, and U. C. Banerjee, "Synthesis of metallic nanoparticles using plant extracts," Biotechnology Advances, vol. 31, no. 2, pp. 346-356, 2013.

[44] H. Chen, J. Wang, D. Huang et al., "Plant-mediated synthesis of size-controllable Ni nanoparticles with alfalfa extract," Materials Letters, vol. 122, pp. 166-169, 2014.

[45] O. Pascu, J. M. Caicedo, J. Fontcuberta, G. Herranz, and A. Roig, "Magneto-optical characterization of colloidal dispersions. Application to nickel nanoparticles," Langmuir, vol. 26, no. 15, pp. 12548-12552, 2010.

[46] J. L. West and N. J. Halas, "Engineered nanomaterials for biophotonics applications: improving sensing, imaging, and therapeutics," Annual Review of Biomedical Engineering, vol. 5, pp. 285-292, 2003.

[47] I. L. Medintz, H. T. Uyeda, E. R. Goldman, and H. Mattoussi, "Quantum dot bioconjugates for imaging, labelling and sensing," Nature Materials, vol. 4, no. 6, pp. 435-446, 2005.

[48] P. K. Jain, X. Huang, I. H. El-Sayed, and M. A. El-Sayed, "Noble metals on the nanoscale: optical and photothermal properties and some applications in imaging, sensing, biology, and medicine," Accounts of Chemical Research, vol. 41, no. 12, pp. 1578-1586, 2008.

[49] S. A. Mamuru and N. Jaji, "Voltammetric and impedimetric behaviour of phytosynthesized nickel nanoparticles," Journal of Nanostructure in Chemistry, vol. 5, no. 4, pp. 347-356, 2015.

[50] S. A. Mamuru, A. S. Bello, and S. B. Hamman, "Annona squamosa leaf extract as an efficient bioreducing agent in the synthesis of chromium and nickel nanoparticles," International Journal of Applied Sciences and Biotechnology, vol. 3, no. 2, pp. 167-169, 2015. 
[51] H. A. Salam, R. Sivaraj, and R. Venckatesh, "Green synthesis and characterization of zinc oxide nanoparticles from Ocimum basilicum L. var. purpurascens Benth.-Lamiaceae leaf extract," Materials Letters, vol. 131, pp. 16-18, 2014.

[52] G. Angajala, R. Ramya, and R. Subashini, "In-vitro antiinflammatory and mosquito larvicidal efficacy of nickel nanoparticles phytofabricated from aqueous leaf extracts of Aegle marmelos Correa," Acta Tropica, vol. 135, no. 1, pp. 19-26, 2014.

[53] S. M. Helen and M. H. E. Rani, "Characterization and antimicrobial study of nickel nanoparticles synthesized from dioscorea (Elephant Yam) by green route," International Journal of Science and Research, vol. 4, no. 11, pp. 216-219, 2015.

[54] M. Fernández-García and J. A. Rodriguez, "Metal oxide nanoparticles," in Encyclopedia of Inorganic and Bioinorganic Chemistry, 2011.

[55] F. T. Thema, E. Manikandan, A. Gurib-Fakim, and M. Maaza, "Single phase Bunsenite $\mathrm{NiO}$ nanoparticles green synthesis by Agathosma betulina natural extract," Journal of Alloys and Compounds, vol. 657, pp. 655-661, 2016.

[56] M. Ghosh, K. Biswas, A. Sundaresan, and C. N. R. Rao, "MnO and $\mathrm{NiO}$ nanoparticles: synthesis and magnetic properties," Journal of Materials Chemistry, vol. 16, no. 1, pp. 106-111, 2006.

[57] X. Deng and Z. Chen, "Preparation of nano-NiO by ammonia precipitation and reaction in solution and competitive balance," Materials Letters, vol. 58, no. 3-4, pp. 276-280, 2004.

[58] Y. Mahaleh, S. K. Sadrnezhaad, and D. Hosseini, "NiO nanoparticles synthesis by chemical precipitation and effect of applied surfactant on distribution of particle size," Journal of Nanomaterials, vol. 2008, Article ID 470595, 4 pages, 2008.

[59] Z. Zhu, N. Wei, H. Liu, and Z. He, "Microwave-assisted hydrothermal synthesis of $\mathrm{Ni}(\mathrm{OH})_{2}$ architectures and their in situ thermal convention to NiO," Advanced Powder Technology, vol. 22, no. 3, pp. 422-426, 2011.

[60] X. Zhang, W. Shi, J. Zhu et al., "Synthesis of porous $\mathrm{NiO}$ nanocrystals with controllable surface area and their application as supercapacitor electrodes," Nano Research, vol. 3, no. 9, pp. 643-652, 2010.

[61] R. Yuvakkumar, J. Suresh, A. J. Nathanael, M. Sundrarajan, and S. I. Hong, "Rambutan (Nephelium lappaceum L.) peel extract assisted biomimetic synthesis of nickel oxide nanocrystals," Materials Letters, vol. 128, pp. 170-174, 2014.

[62] M. R. Salvadori, C. A. O. Nascimento, and B. Corrêa, "Nickel oxide nanoparticles film produced by dead biomass of filamentous fungus," Scientific Reports, vol. 4, article 6404, 2014.

[63] S. Sathyavathi, A. Manjula, J. Rajendhran, and P. Gunasekaran, "Extracellular synthesis and characterization of nickel oxide nanoparticles from Microbacterium sp. MRS-1 towards bioremediation of nickel electroplating industrial effluent," Bioresource Technology, vol. 165, pp. 270-273, 2014.

[64] M. R. Salvadori, R. A. Ando, C. A. O. Nascimento, and B. Corrêa, "Extra and intracellular synthesis of nickel oxide nanoparticles mediated by dead fungal biomass," PLOS ONE, vol. 10, no. 6, Article ID e0129799, 2015.

[65] M. Ullah, A. Naz, T. Mahmood, M. Siddiq, and A. Bano, "Biochemical synthesis of nickel \& cobalt oxide nano-particles by using biomass waste," International Journal of Enhanced Research in Science Technology \& Engineering, vol. 3, pp. 415422, 2014 

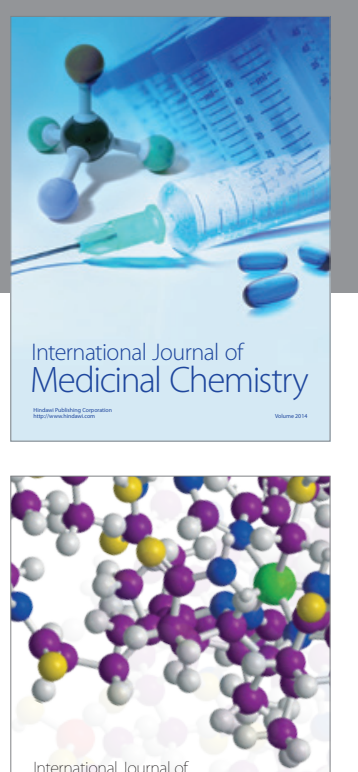

Carbohydrate Chemistry

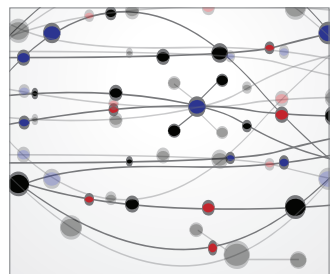

The Scientific World Journal
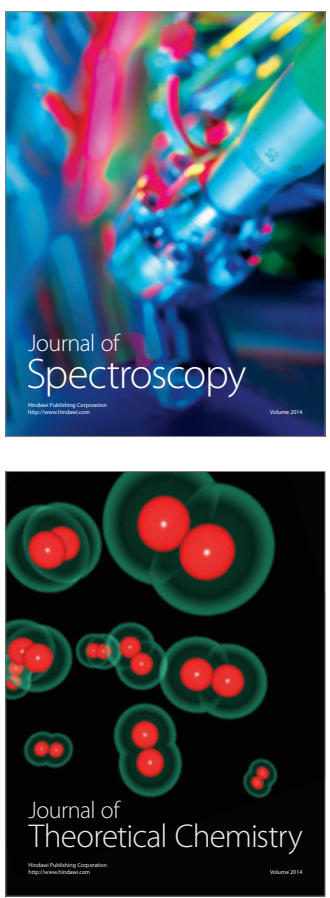
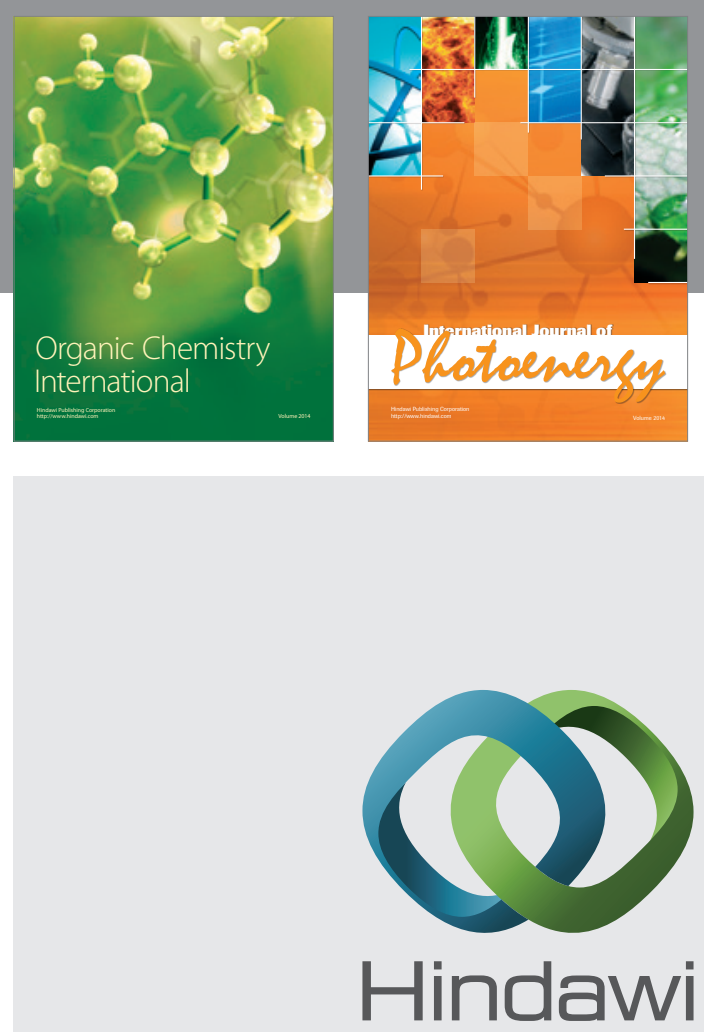

Submit your manuscripts at

http://www.hindawi.com

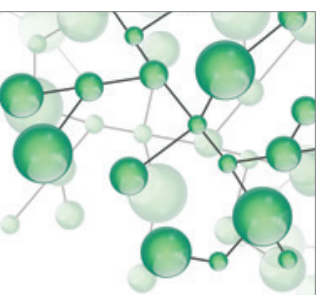

International Journal of

Inorganic Chemistry

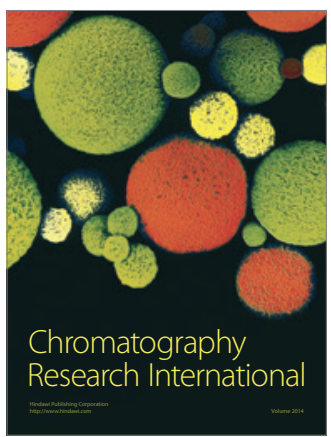

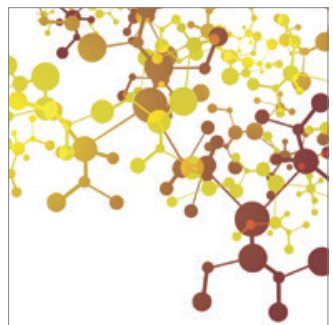

Applied Chemistry
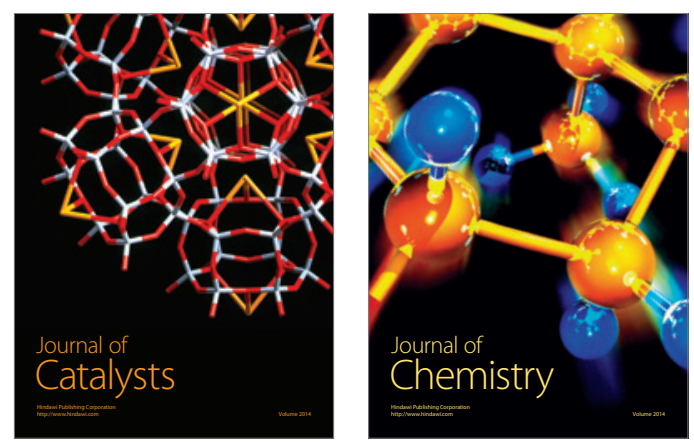
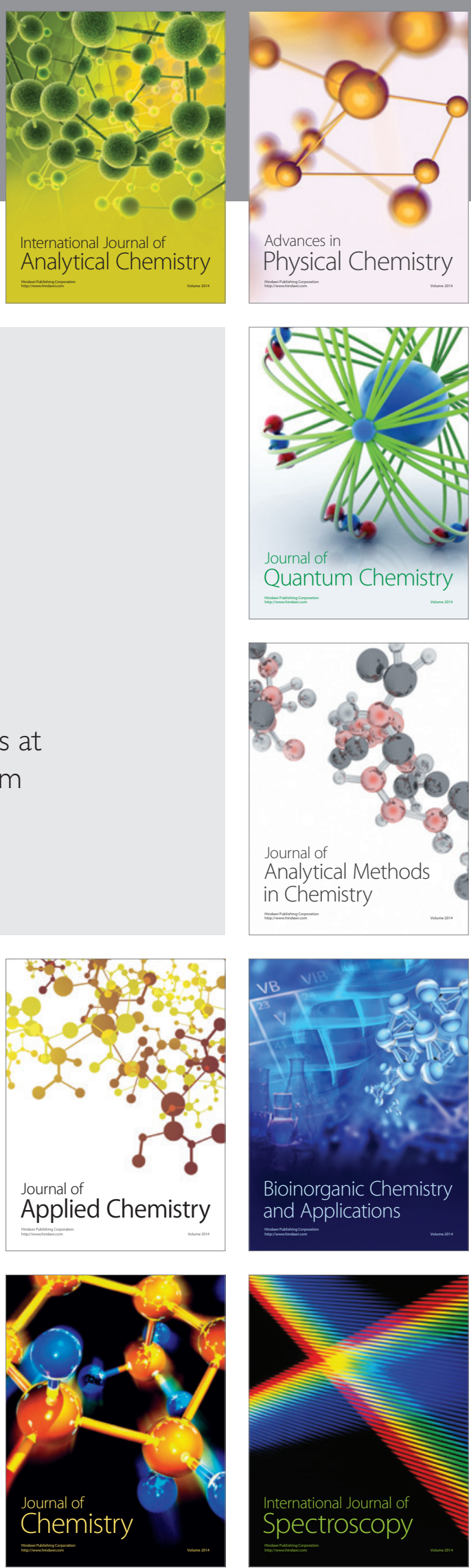